\title{
Postentübasyon trakeal stenoz
}

\author{
Efsun Gonca UĞUR \\ CHOUSEIN ${ }^{1}$ \\ Mehmet Akif ÖZGÜL ${ }^{1}$
}

1 İstanbul Yedikule Göğüs Hastalıkları ve Göğüs Cerrahisi Eğitim ve Araştırma Hastanesi, Göğüs Hastalıkları Kliniği, İstanbul, Türkiye

${ }^{1}$ Clinic of Chest Diseases, Istanbul Yedikule Chest Diseases and Thoracic Surgery Training and Research Hospital, Istanbul, Turkey

\section{ÖZET}

\section{Postentübasyon trakeal stenoz}

Postentübasyon trakeal stenoz (PETS); son yıllarda yoğun bakım yataklarının ve endotrakeal entübasyon gerektiren endikasyonların artışı, bu konuda farkındalı̆̆ın artması nedeniyle eskiye nazaran daha sık görmeye başladığımız iyatrojenik bir komplikasyondur. PETS, asemptomatik olabilecek olgulardan, çok acil girişimsel müdahale gerektirecek kadar ağır olgulara varan geniş bir klinik yelpazeye sahiptir. Bu nedenle anamnezinde entübasyon olan, solunum sıkıntısı tarifleyen hastaların ayırıcı tanısında mutlaka akılda tutulmalıdır. Tanıda altın standart fiberoptik/rijid bronkoskopidir. Tedavisinde ilk tercih edilen yöntem trakeal rezeksiyon ve uç uca anastomoz (TRA) olsa da cerrahiye uygun olmayan ya da bazı özel seçilmiş olgularda bronkoskopik girişimler hayat kurtarıcı, cerrahiye kadar geçecek sürede hastaya zaman kazandırııı ve hatta kür sağlayııı olmaktadır.

Anahtar kelimeler: Entübasyon; trakeal stenoz; bronkoskopi

\section{SUMMARY}

\section{Postintubation tracheal stenosis}

Postintubation tracheal stenosis (PITS) is an iatrogenic complication seen increasingly often as the number of intensive care unit (ICU) bed multiply, the indications for endotracheal intubation expand and disease awareness rises. PITS has a clinical severity spectrum ranging from asymptomatic cases to patients requiring urgent interventional procedures. It should therefore always be considered in the differential diagnosis in patients with a history of intubation who present with the complaint of difficult breathing. The golden standart for diagnosis is fiberoptic/rigid bronchoscopy. Even though tracheal resection and end-to-end anastomosis (TRA) is the preferred traetment, in some selected cases and in the patients who are not candidates for surgery, bronchoscopic interventions can be life saving, temporizing until surgery is possible and even be curative.

\section{Yazışma Adresi (Address for Correspondence)}

Key words: Intubation; tracheal stenosis; bronchoscopy

\section{Dr. Efsun Gonca UĞUR CHOUSEIN}

İstanbul Yedikule Göğüs Hastalıkları ve Göğüs Cerrahisi Eğitim ve Araştırma Hastanesi, Göğüs Hastalıkları Kliniği, ISTANBUL - TÜRKIYE

e-mail: efsungoncachousein@yahoo.com 


\section{Giriş}

Postentübasyon trakeal stenoz (PETS) ilk kez 1800'lü yıllardan itibaren varlığından bahsedilen, sonradan posttrakeostomi trakeal stenoz (PTTS)'un da tariflenerek bu gruba eklendiği, geçmişte nadir olarak nitelendirilse de tıptaki gelişmelerle birlikte hem entübasyon gerektiren endikasyonların artışı hem de bu entübasyonlar sonrası PETS oluşabileceği farkındalığının artması ile günümüzde girişimsel bronkolojide daha sık gözlenen önemli bir iyatrojenik komplikasyondur (1-3). PETS, benign trakeal stenozlar içinde en sık rastlanan stenoz şeklidir.

Hastaların asemptomatik olabileceği göz önüne alınacak olursa sıklığı ile ilgili net bir rakam verilemese de entübe olan tüm hastaların \%63'ünde çeşitli trakeal hasar gelişebileceği, \%10-11'inde trakeal stenoza rastlanabileceği, tüm entübe olmuş hastaların trakeal stenoz nedeniyle sadece \%1-2'sinin semptomatik olabileceği bildirilmiştir. Yapılan prospektif bir çalışmada entübasyona bağlı trakeal stenoz gelişme oranının $\% 19$, trakeostomiye bağlı trakeal stenoz gelişme oranının \%65 olduğu saptanmıştır (2,4-6).

\section{RISK FAKTÖRLERI ve PATOGENEZ}

PETS'nin en sık nedenleri, entübasyon ve trakeostomi ile ilişkili iyatrojenik travmadır. Trakeaya yapılan acil girişimler sırasında kıkırdak halkanın ve komşu dokunun hasarlanması veya yüksek açılmış trakeostomi yeri, yüksek cuff basıncı, uzamış entübasyon, sık aspirasyon gerekliliğine bağlı irritasyon PETS için önemli risk faktörleridir. Bu faktörler ilk olarak trakeanın kıkırdak halkası üzerindeki mukozasında hasara ve iskemik nekroza yol açar. Bu patolojik durum sonra daha derin dokuların da sürece katılmasıyla granülasyon dokusu ve fibrozise ilerler, submukozal ve mukozal tabakada kalınlaşma ve böylece trakea lümeninde stenozla sonuçlanır (7-10).

Günümüzde geniş volümlü, düşük basınçlı kaf kullanılmasına ve yoğun bakım şartlarındaki iyileşmeye rağmen PETS görülmeye devam etmektedir $(7,11)$. PETS; çoğunlukla uzamış endotrakeal entübasyon süresinin bir sonucu olarak bildirilse de çok kısa süreli entübasyonlar sonrası da PETS gelişen olgular bildirilmektedir $(8,12)$.

Seriden seriye değişmekle birlikte genelde serilerde kadın cinsiyet üstünlüğü göze çarpmaktadır $(13,14)$. Düşük kan basıncı, diyabet, obezite, kardiyovasküler hastalık varlığı, reflü, anemi, nötropeni, kadın cinsiyet, entübasyon tüpünün içeriğinde ve yerleştirilmesinde kullanılan kimyasal maddelere karşı kişinin hassasiyeti olması, kortikosteroid kullanımı, ileri yaş, sekresyon fazlalığı, infeksiyon, ciddi solunum yetmezliği, otoimmün hastalıklar, uyku apnesi, farenks ya da larenks kanseri için radyoterapi almış olmak da risk faktörleri olarak tanımlanmıştır $(5,13-15)$. Derin sedasyon uygulanmayan hastalarda, olası trakeal irritasyona bağlı olarak PETS daha sık görülmüştür (16).

\section{TANI}

\section{Anamnez ve Fizik Muayene}

Tanıda ilk aşama her zaman şüphedir. Anamnezinde yoğun bakım yatışı olan hastada, sonrasında nefes darlı̆̆ı, horlama ya da tekrarlayan infeksiyonlar söz konusu olduğunda PETS akla getirilmelidir.

Trakeadaki darlığın yerine, derecesine göre semptomlar değişebilir. Sıklıkla, başlangıçta sadece egzersiz anında nefes darlığı olurken zamanla nefes darlığı istirahatte bile hissedilir olabilir. Öksürük ve whezing de sıktır. Hava yollarındaki darlık, balgam çıkarmada güçlüğe ve tekrarlayan infeksiyonlara neden olabilir.

Dispne ve whezing birlikteliği olan hastalar yanlışlıkla astım, bronşit ya da kronik obstrüktif akciğer hastalığı $(\mathrm{KOAH})$ tanıları alabilirler. Bronkodilatöre yanıt alınamayan dispneler bu nedenle gözden kaçırılmamalıdır.

Daralmıs trakeada sorun yaratan bir sekresyon ya da kanama olmadıkça genelde akut bir tablo ortaya çıkmayabilir.

Solunum sistemi muayenesi darlık çok kritik orana gelmedikçe, istirahat halindeyken genellikle normaldir. Stridor, trakea çapı $5 \mathrm{~mm}$ 'nin altına inince ortaya çıkar. Trakeostomi skarı varlığı hastalıktan şüphelenmek için bir ipucu olabilir. Hasta yoğun bakım yatışı sonrası çok kısa sürede semptomatik hale gelebileceği gibi bazen de semptomların orta çıkması ayları hatta yılları alabilir $(3,13)$.

\section{Görüntüleme}

Tanının ikinci aşaması görüntülemedir. En basit görüntüleme yöntemi PA akciğer grafisidir (Resim 1). PA akciğer grafisi genelde normal saptanmakla birlikte, trakea lümenine ait hiperlüsen alanda düzensizlik görülebilir (Resim 2).

Diğer bir görüntüleme yöntemi bilgisayarlı tomografidir (Resim 3,4). Özellikle iki boyutlu kesitler elde edildiğinde trakeayı doğru bir şekilde görüntülemeye yarayan, noninvaziv bir yöntemdir. Darlığın lokalizasyonunu, tipini, boyutlarını, damarsal yapılarla ilişkisini, kıkırdak yapının bütünlüğünü ve distal hava yolla- 


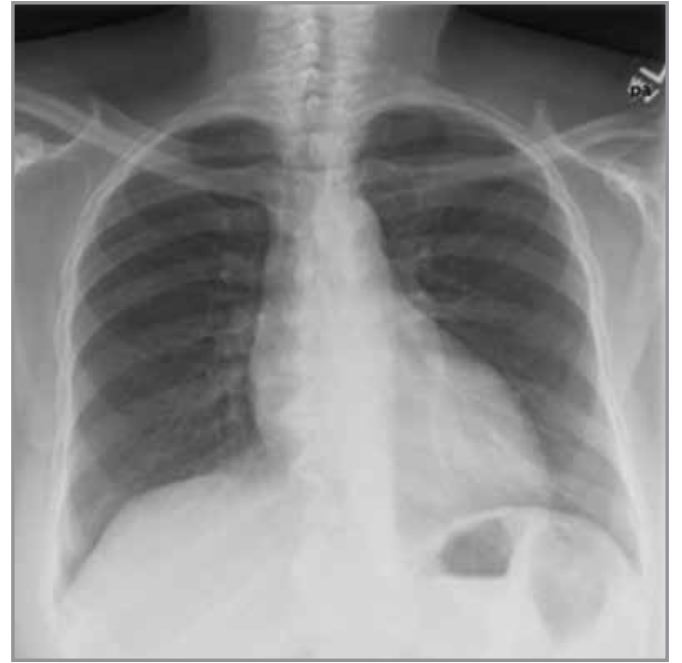

Resim 1. PETS; PA akciğer grafisi.

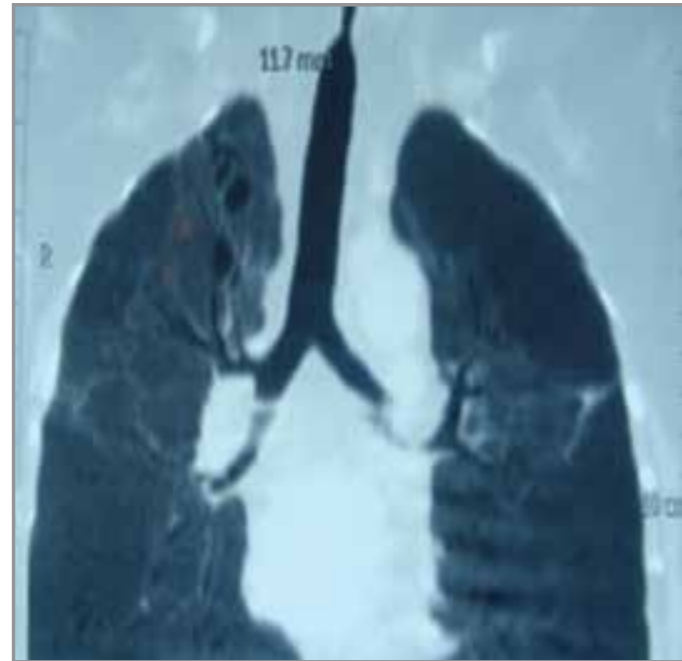

Resim 2. PETS; rekonstrüksiyonda trakeadaki hava sütununun daralmış görünümü.

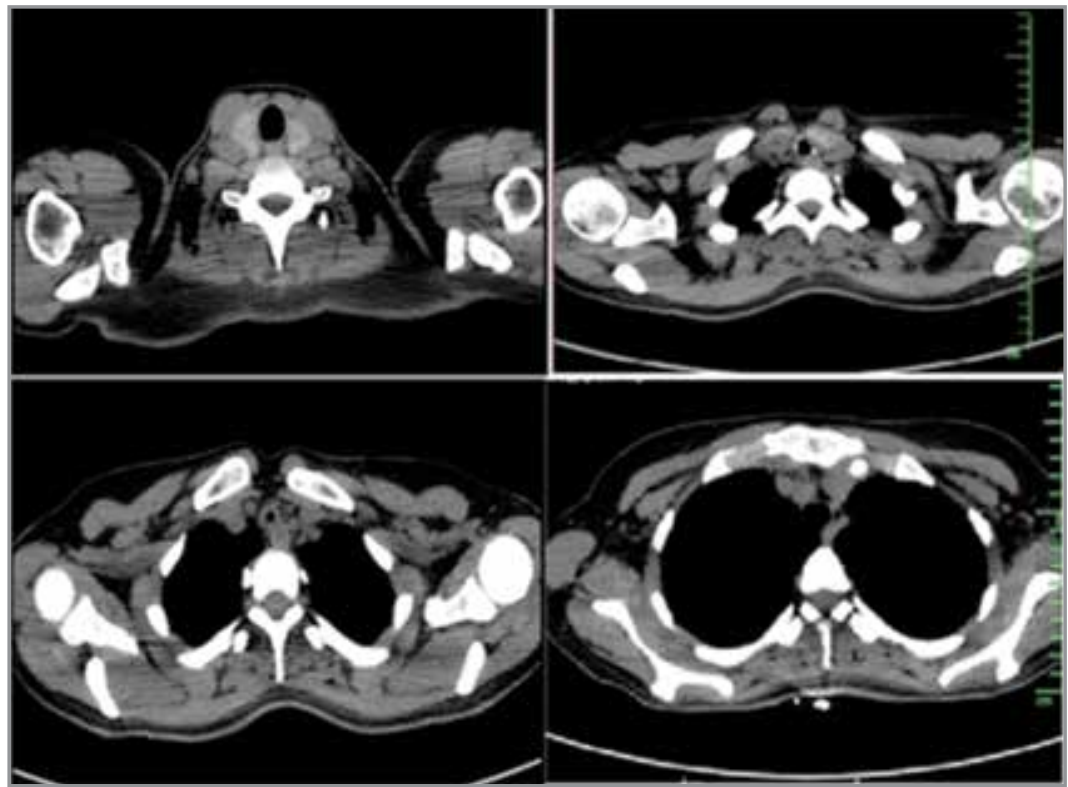

Resim 3. PETS; toraks BT kesitleri.
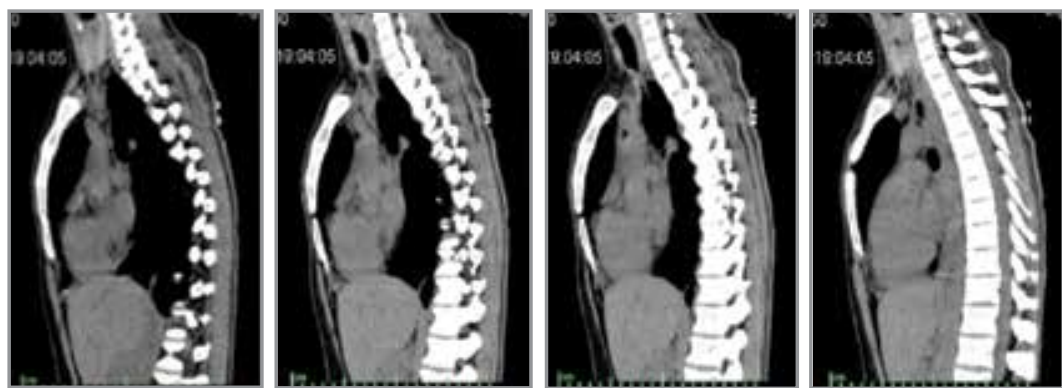

Resim 4. PETS; toraks BT; sagittal kesit. 
rını özellikle de girişimsel işlemler öncesi daha iyi değerlendirmeyi sağlar. Sonradan teknik olarak elde edilebilecek "sanal bronkoskopik görüntüler" de değerlendirmeye katkı sağlayabilir (17).

\section{Solunum Fonksiyon Testleri}

Dispne yakınması olan bir hastada solunum fonksiyon testlerindeki akım volüm halkası çoğu zaman olmasa da büyük hava yolu obstrüksiyonunu, derecesini ve darlığın yeri (ekstratorasik ya da intratorasik obstrüksiyon) hakkında yol gösterici olabilir (Şekil 1) (18).

\section{Bronkoskopi}

Bronkoskopi PETS'nin tanısında altın standarttır. Fiberoptik bronkoskopi de rijid bronkoskopi de, darlığın yerinin, derecesinin, uzunluğunun ve darlığın tipinin görülmesini sağlar. Mukoza ve eşlik eden diğer patolojiler değerlendirilebilir (Resim 5,6). Fleksibl bronkoskopi tedaviden ziyade, sıklıkla rijid bronkoskopi öncesi darlığın değerlendirilmesi amacıyla kullanılmaktadır. Son yıllarda PETS'lerin değerlendirilmesi ve tedavisinde de rijid bronkoskopi kullanımı daha çok tercih edilmeye başlanmıştır (19).

\section{STENOZ SINIFLAMALARI}

Bronkoskopi ile tanı koyduğumuz trakeal stenozun morfolojisini, vokal kordlara ana karinaya mesafesini tariflemek hem klinisyenler arasında ortak bir dil oluşturmak hem de tedavi için gerekli planlamayı yapmakta faydalıdır (20).

Stenozun sınıflamasında tek bir sınıflandırma sistemi bulunmamaktadır. Pek çok araştırmacı tarafından farklı boyutlarda ele alınarak stenoz sınıflamaları yapılmıştır. Bir araştırmacı, entübasyon sonrası trakeada izle-

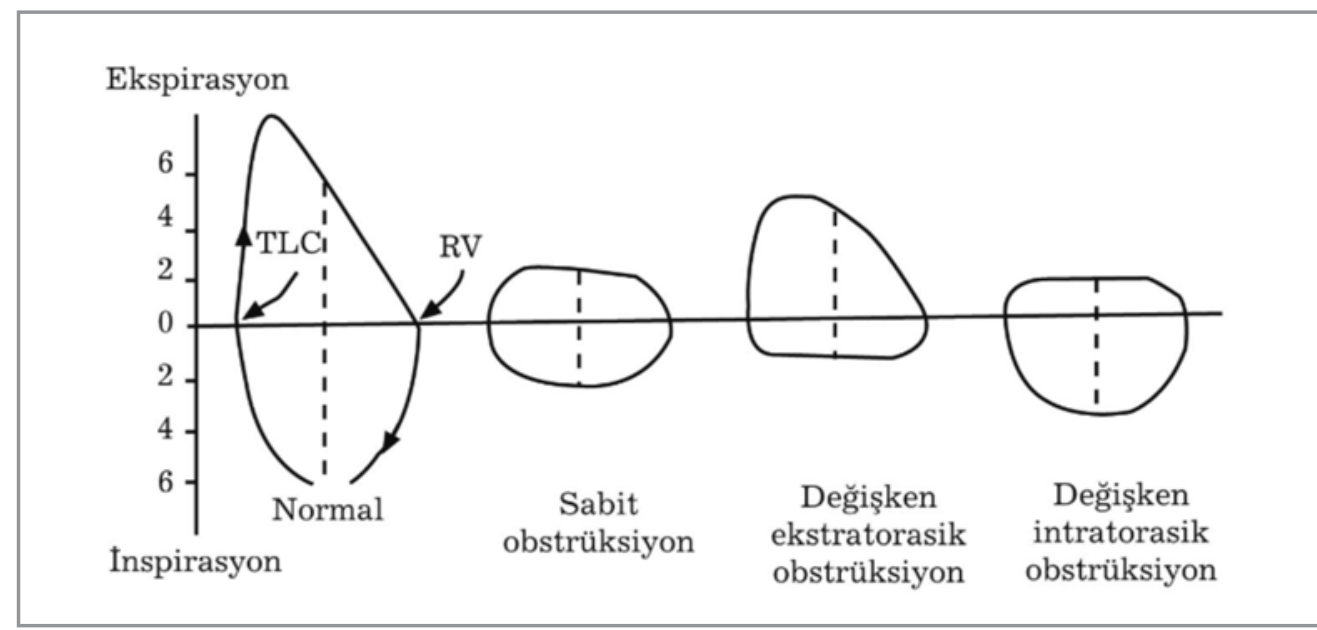

Şekil 1. Solunum fonksiyon testi.

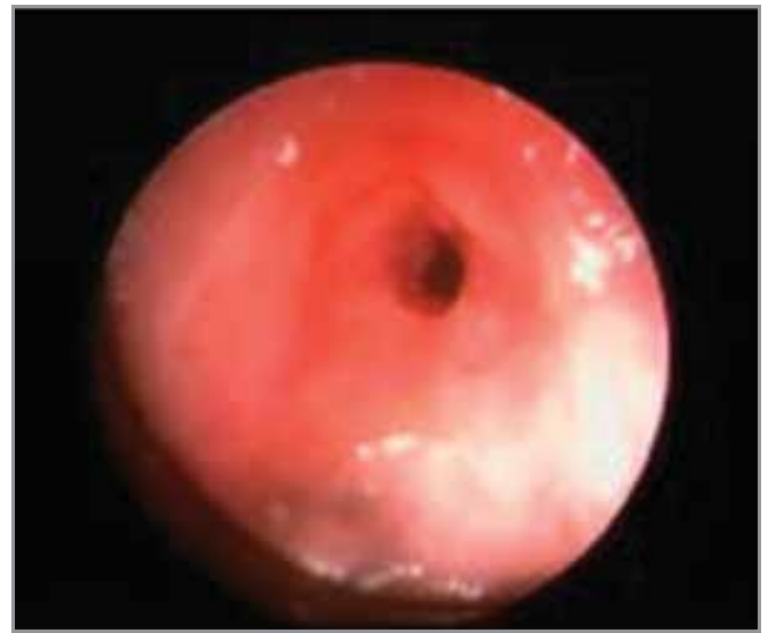

Resim 5. PETS; bronkoskopik görüntü.

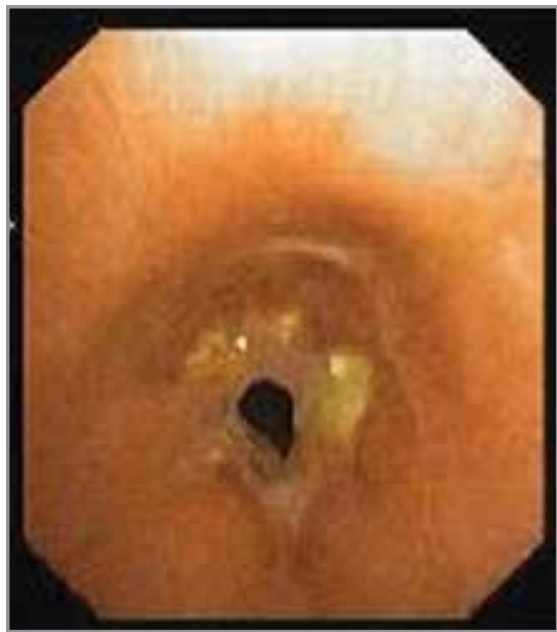

Resim 6. PETS; rijid bronkoskopide görüntü. 
nen obstrüktif lezyonların yerini göz önüne alarak, stoma bölgesi, cuff bölgesi, cuff ile stoma arasındaki bölge ve tüpün ucunun trakeaya temas ettiği noktayı baz alarak sınıflama yaparken, bir diğeri darlığın morfolojisine göre stenozu sınıflandırmıştır $(21,22)$.

Günlük pratikte en sık kullanılan ve kabul gören, Brichets ve arkadaşlarının yaptığı gibi basit ve kompleks olmak üzere stenozları ikiye ayırmaktır. Buna göre; uzunluğu $1 \mathrm{~cm}$ 'den az olan, web-like stenozlar (ince halka şeklinde soluk membranöz alan) ve granülomlar basit, $1 \mathrm{~cm}$ 'den uzun, fibrozisin eşlik ettiği, kıkırdak hasarı ve malazinin eşlik ettiği darlıklar kompleks stenoz olarak sınıflanır (Resim 7,8) (22).

Myer ve arkadaşları yaptıkları sınıflamada bronkoskop ile trakea çapını karşılaşıımayı tercih etmişken, Mc Caffrey subglottik alana olan mesafeyi ve stenozun trakeadaki uzunluğunu ele alarak sınıflama yapmıştır (Şekil 2,3) $(23,24)$.

\section{POSTENTÜBASYON TRAKEAL STENOZDA TEDAVI}

PETS tanılı operabl hastada ilk tercih edilen tedavi trakeal rezeksiyon ve uç uca anastomoz (TRA). Grillo ve arkadaşlarının çalışmasında 503 hastanın \%93.7'sinde cerrahi sonrası başarı oranı \%94 olarak bulunmuştur. Cerrahi sonrası en sık rastlanan komplikasyonlar granülasyon dokusu oluşumu (\%9.7), yara yeri infeksiyonu (\%3), glottik disfonksiyon (\%2.2), açılma ve restenozis $(\% 5.7)^{\prime}$ dir. Mortalite oranı \%2.4 olarak saptanmıştır (25).

Illk tercih edilen cerrahi yöntem TRA iken, krikotrakeal rezeksiyon (KTR)'da uygulanabilmektedir. KTR'de

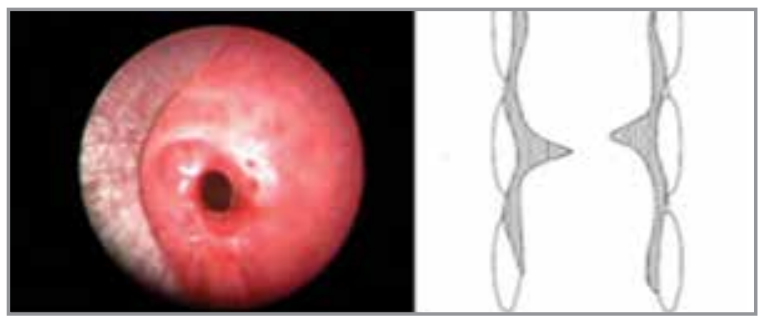

Resim 7. PETS; web-like.

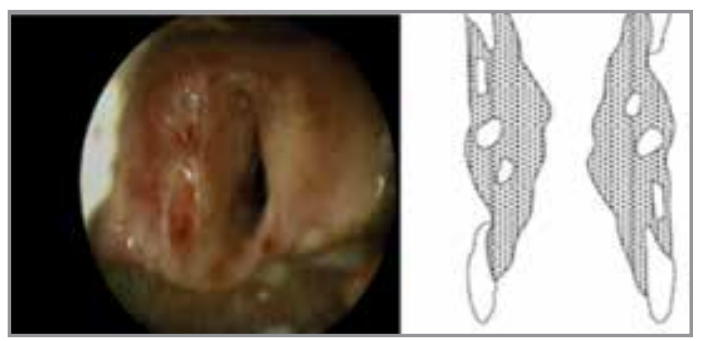

Resim 8. PETS; kompleks. başarı oranı oldukça yüksektir (\%96.6), mortalite oranı \%3.3'tür (26). PETS'de ilk tercih edilen tedavi cerrahi olsa da acil durumlarda (ki bu konuda genel kabul trakea çapının 5 mm'den daha dar olduğu durumlardır) ve cerrahi tedavi olamayacak hastalarda bronkoskopik yöntemler tercih edilebilir. Acil olmayan durumlarda, cerrahi bir kontrendikasyonu olmayan hastalarda darlığın kalıcı tedavisi olarak bronkoskopik yöntemlerin seçilmesi konusu hala tartışmalıdır. Ancak acil durumlarda trakeal darlığın hızla ortadan kaldırıl-

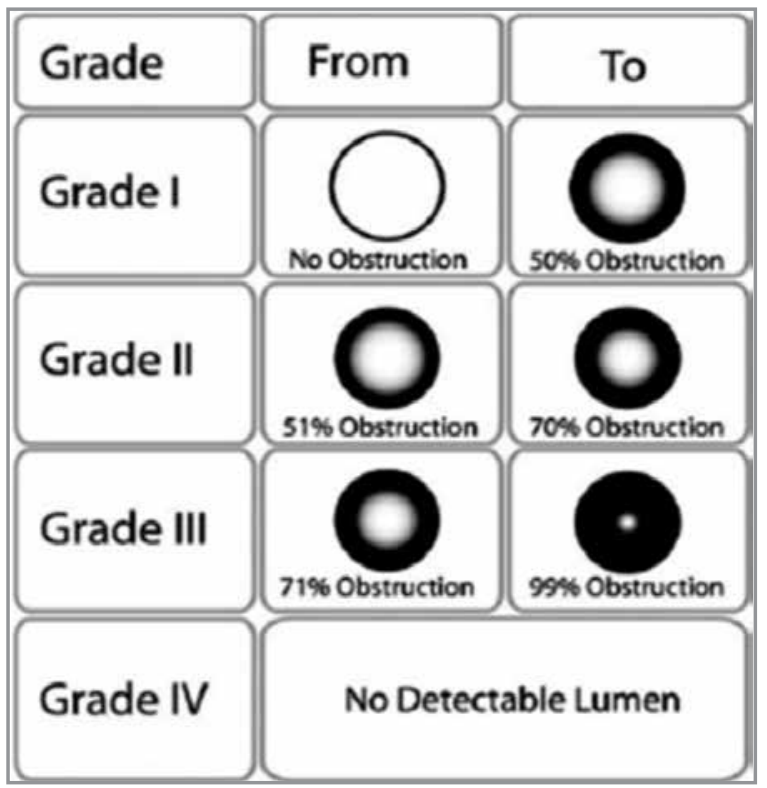

Şekil 2. Cotton-Myer PETS sınıflaması.

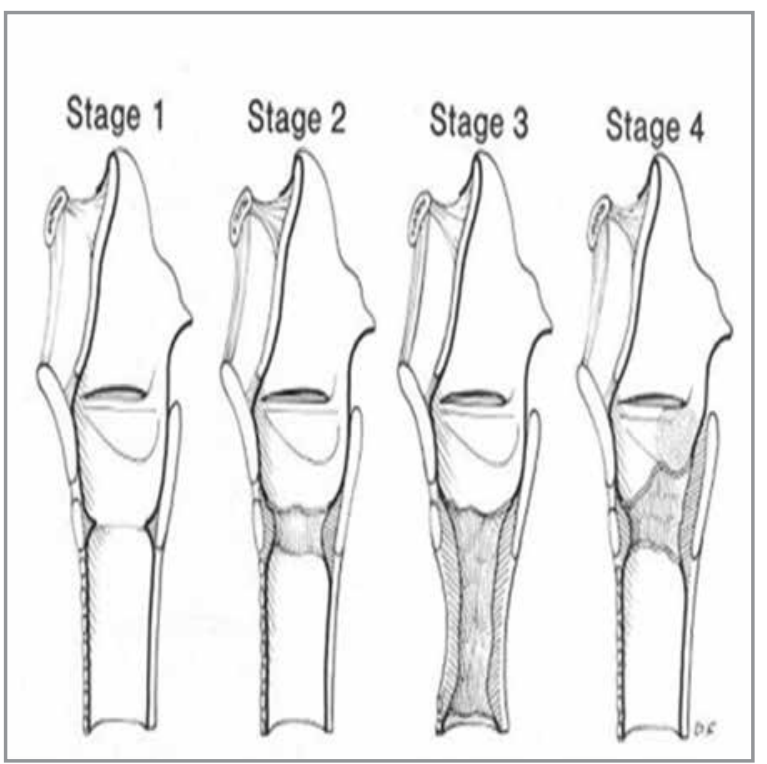

Şekil 3. Mc Caffrey PETS sınıflaması. 
ması ve operasyona kadar hastaya zaman kazandırılması için bronkoskopik dilatasyon tercih edilmeli ve acil trakeostomiden kaçınılmalıdır. Böyle bir durumda fiberoptik bronkoskopi değil direkt rijid bronkoskopi ile işlem uygulanmalıdır ya da fiberoptik bronkoskop kullanılsa bile rijid bronkoskop hemen uygulayıcının yanı başında hazır olmalıdır $(19,22,27,28)$. PETS'nin bronkoskopik tedavisinde ilk aşamadaki amaç hava yolunun açıklığının sağlanması ve sonrasında hava yolunun açıklığının korunmasıdır.

\section{Hava Yolu Açıklı̆̆ının Sağlanması}

Hava yolunun açıklığının sağlanmasında kullanılan metotları üç grupta toplayabiliriz:

1. Mekanik dilatasyon (rijid tüpün kendisi, balon, buji ve kesi),

2. Soğuk yöntemler (kriyoterapi),

3. Sıcak yöntemler [argon plazma koagülasyon (APC), laser, elektrokoter] (29).

Mekanik dilatasyon: Artan çapta rijid tüpler kullanılarak yapılan bu dilatasyon yöntemi hızlı yanıt alınması, kısa süre içerisinde yapılabilir olması, tekrarlanabilir olması nedeniyle hayat kurtarıcı özelliğiyle de en sık kullanılan, tecrübeli ellerde yapılırsa da oldukça güvenli olan bir yöntemdir (Resim 9). Balon kateter ve buji ile darlık bölgesi dilate edilebilir. Yine web-like stenozlarda kullanılabilen, saat 11 ve 13 hizalarında darlık alanına kesi yapılması da bir diğer tercih edilen yöntemdir. Mekanik dilatasyon yöntemlerinin başarı oranı \%40-100'dür. Laserasyon, rüptür, pnömotoraks, pnömomedastinum, hemoraji gibi komplikasyonlar görülebilir (30).

\section{Soğuk Yöntemler:}

Kriyoterapi: İçerisinde nitröz oksit, karbondioksit ve SIVI nitrojen ihtiva eden dondurma yöntemidir. -40, -60 dereceye kadar dokuyu soğutur. iç̧erisinde su içeren dokularda koagülasyon nekrozuna yol açarak etki eder. Etkisi geç ortaya çıkar. Çalışmalarda çok etkili bulunmasa da işlem tekrar sıklığını azalttığına dair veriler mevcuttur $(29,31,32)$.

\section{Sıcak Yöntemler:}

Argon plazma koagülasyon: Direkt temas gerektirmeyen, kullanımı kolay, hızlı etki eden, trakea duvarında derin penetrasyonu olmadığı için düşük komplikasyon ve kanama riskine sahip bir termal tedavi yöntemidir. PETS'de de kullanıma uygundur $(29,33)$.

Elektrokoter: Darlık alanını saat 3, 6 ve 9 yönlerinde keserek, koagüle eden bir diğer termal tedavi yöntemidir. Ancak perforasyon riski yüksek olduğu için çok dikkatli kullanılmalıdır, tüm diğer termal tedavi yöntemlerindeki gibi kanama açısından güvenli bir yöntemdir $(29,34)$.

Laser: İşlem yapılan alanı koagüle ederek etki eden bu yöntem hızlı etkili olması, düşük kanama riski nedeniyle PETS'de tercih edilebilecek yöntemlerdendir. $\mathrm{Nd}$-YAG, $\mathrm{CO}_{2}$, Diot olmak üzere farklı tipleri vardır $(29,35)$.

\section{Hava Yolu Açıklığının Korunması}

Hava yolu açıklığı sağlandıktan sonraki aşamada hava yolunun açıklığının devamı sağlanmalıdır. Bu amaçla kullanılan yöntemler ise stentler, mitomisin-C ve steroid kullanımıdır.

Stentler: Cerrahiyi kabul etmeyen ya da inoperabl olgularda hem palyasyon, hem kür, hem de bazı hastalarda cerrahiye kadar geçecek zamanda hastaya zaman kazandırmak amaçlı, hava yolunda açıklık sağlamak ve hava yoluna destek amaçlı kullanılan araçlardır. Hızlı etkili bir tedavi yöntemidir. Metal ve silikon olmak üzere iki çeşit stent vardır. PETS'ler benign nedenli stenozlar olduğu için gereğinde çıkarılabileceğinden uygulamada metal stentler değil silikon stentler tercih edilir (Resim 10). Stenozun uzunluğu dikkate alınarak düz stentler (silikon, polifleks) kullanılabilir (Resim 11).
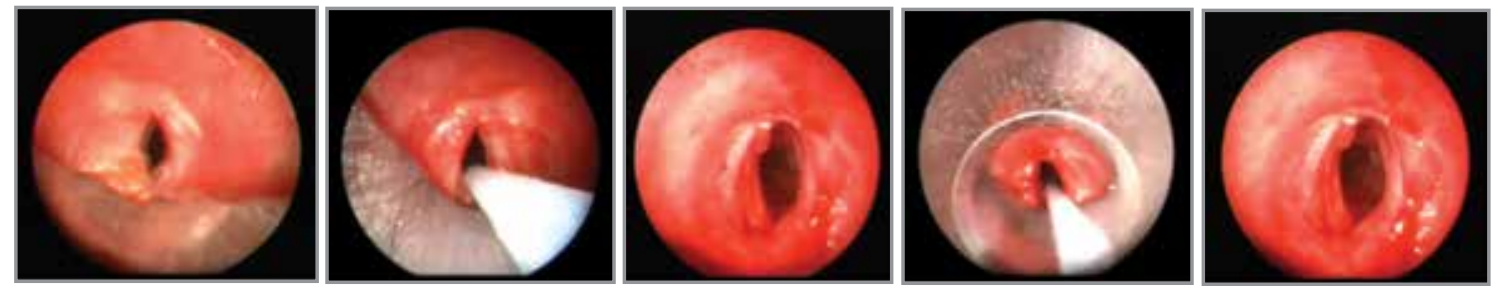

Resim 9. PETS; mekanik dilatasyon aşamaları. 
Geçmişte kullanılan düz trakeal silikon stentlerde migrasyon sık iken, artık günümüzde kum saati şekilli silikon stenotik stentlerin kullanıma girmesiyle bu risk de oldukça azalmıştır (36-38) (Şekil 4) (Resim 12-17).

Mitomisin-C: DNA sentezini inhibe ederek, fibroblast ve kollajen proliferasyonunu engelleyen antrasiklin

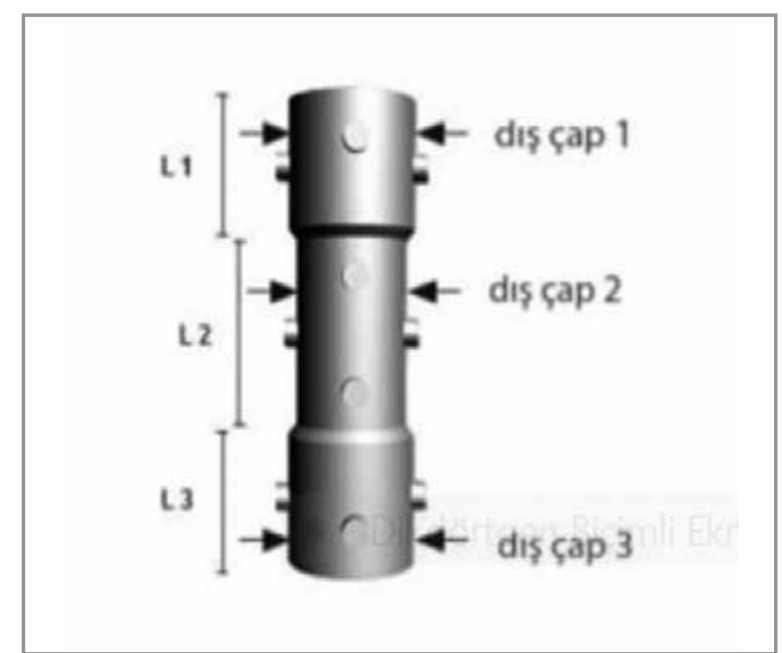

Şekil 4. Stenotik trakeal stent.

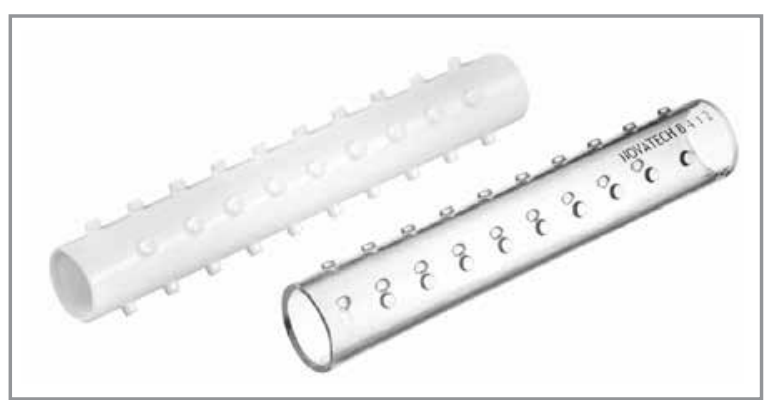

Resim 10. Düz silikon trakeal stent.

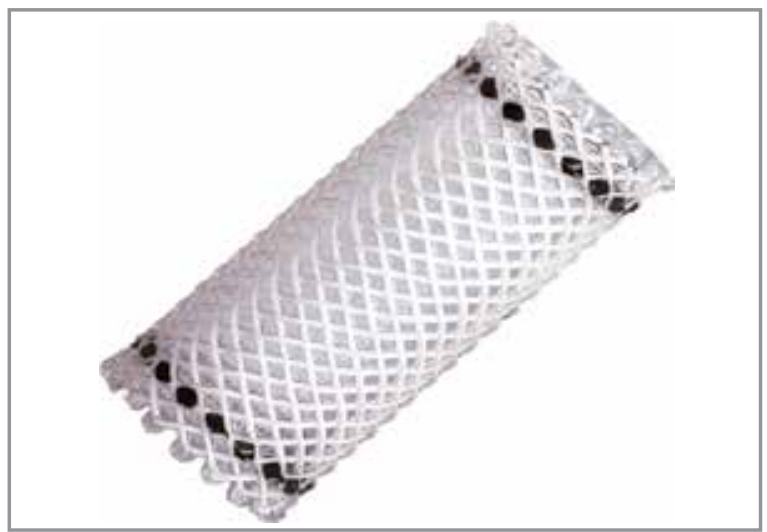

Resim 11. Polifleks stent.

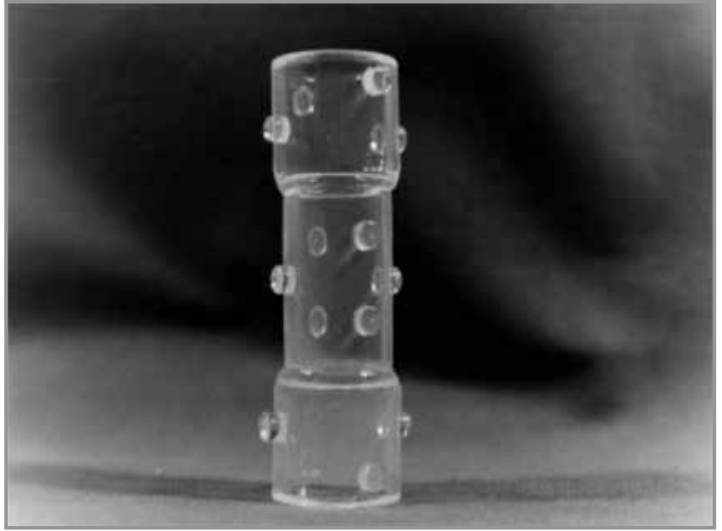

Resim 12. Silikon stenotik trakeal stent.

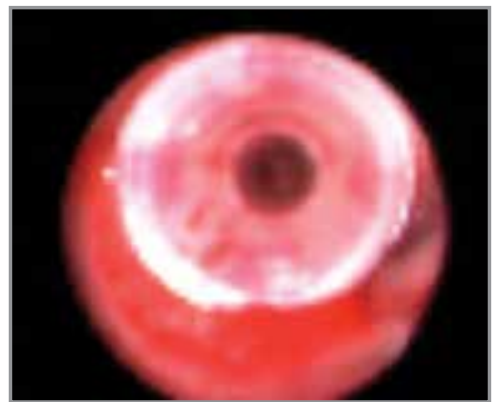

Resim 13. Stent proksimali.

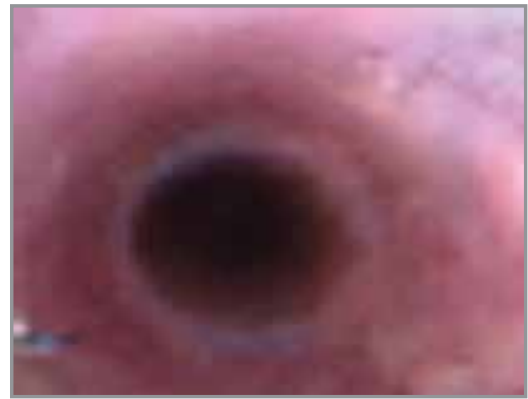

Resim 14. Stentin içi.

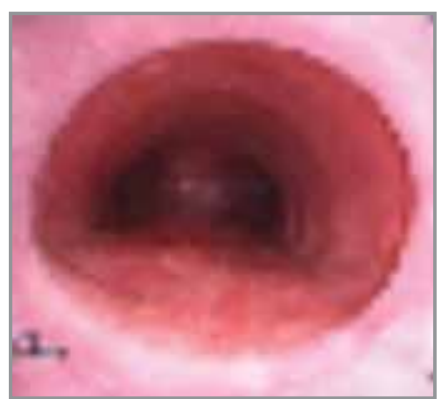

Resim 15. Stent distali. 


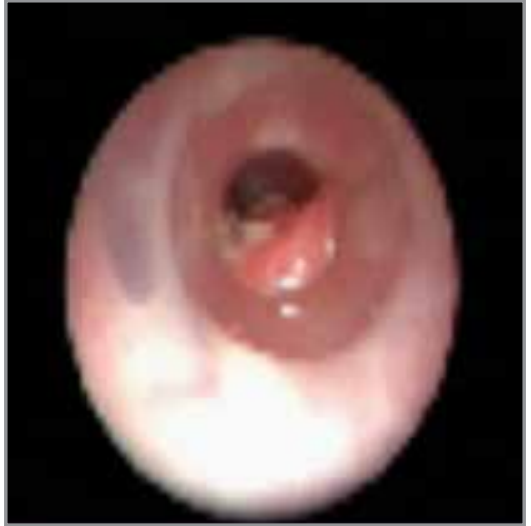

Resim 16. Stent distalinde granülasyon dokusu.

antibiyotiktir. Topikal olarak kullanılan, uygulaması kolay ve kısa olan, geç etkisi ortaya çıktığı iddia edilen bir ajandır. PETS'de efektivitesi şüpheli olmakla birlikte yukarıda bahsettiğimiz diğer tedavilerle kombine kullanımının tedavide başarıyı artırdığına dair bulgular vardır. Merkezden merkeze değişen, $0.4 \mathrm{mg} / \mathrm{mL}$ ile 2.0 $\mathrm{mg} / \mathrm{mL}$ arasında değişen dozlarda kullanımı bildirilmiştir (39).

Kortikosteroidler: Kortikosteroidlerin PETS'de tek başına kullanımı söz konusu değildir. Diğer tedavi seçenekleri ile kombine edilerek kullanılır. Sık tekrarlanan bronkoskopik dilatasyon sayısını, rezeke edilecek darlık alanını ve cerrahi rezeksiyon gereksinimini azalttığına dair ümit verici bilgiler vardır (40).

\section{Multimodalite Tedavinin Önemi}

Şu ana kadar bahsedilen endoskopik tedaviler tek başlarına elbette uygulanabilir. Ancak multimodalite tedavi dediğimiz, birden fazla tekniğin bir arada kullanıldığı durumlarda tedavi başarısının daha yüksek olduğu bilinmektedir $(22,41,42)$.

\section{POSTENTÜBASYON TRAKEAL STENOZLARDA TAKIP}

Web-like (basit) PETS'lerde ve kompleks tip PETS'de tedavi ve takip farklıdır. Web-like stenozu olan bir hastada tedavide ilk seçenek girişimsel bronkolojik

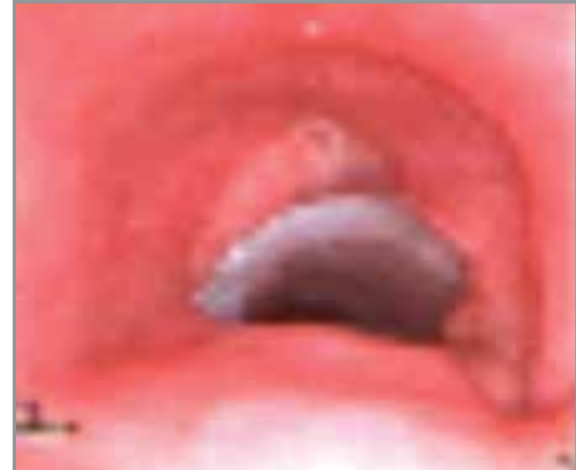

Resim 17. Stent migrasyonu.

yaklaşımdır. Darlık alanı artan çapta rijid tüplerle dilate edilir. Topikal uygulamalarla tedavi kombine edilir. Belirli aralıklarla ve hastanın semptomları gerektirdikçe bronkoskopi, solunum fonksiyon testi ve radyolojik kontrolleri planlanır. Genelde girişimsel işlem sonrası dönemde 24 aylık bir takip önerilir ve bu takip süresi içerisinde darlıkta rekürrens yoksa hasta takipten çıkarılır. Ancak tekrarlayan darlık durumunda bronkoskopik dilatasyon üç kereye kadar tekrarlanır. Üçten fazla dilatasyon gerektiğinde artık hasta kompleks tipte stenoz gibi ele alınarak; cerrahiye uygunluk açısından değerlendirilir. Cerrahi olamayacaksa stent yerleştirilir. Kompleks tip stenozlarda ise hasta öncelikle cerrahi açısından değerlendirilmelidir. Cerrahiye uygun hastalara TRA uygulanır. Cerrahiye uygun olmayan ya da cerrahiyi kabul etmeyen hastalara dilatasyonun ardından stent uygulaması yapılır. İnoperabl hastalar stent ile 24 aya kadar takip edilir. Bu süre içerisinde stentin çıkarılması denenebilir. Ancak bu deneme ile ilgili belirtilmiş literatürde net bir süre olmamasına rağmen 6. ayda uygun süre olarak belirtilmektedir. Darlıkta nüks olursa tekrar uygulanabilir. illk uygulama anında operabl olmayan hastalar, takiplerinde operabl hale gelmeleri durumunda 6 ay- 1 yıl sonra stent çıkarılmadır. Stent çıkarıldığında rekürrens gelişirse hasta cerrahi açıdan tekrar değerlendirilmelidir (Şekil 5) $(22,43,44)$. 


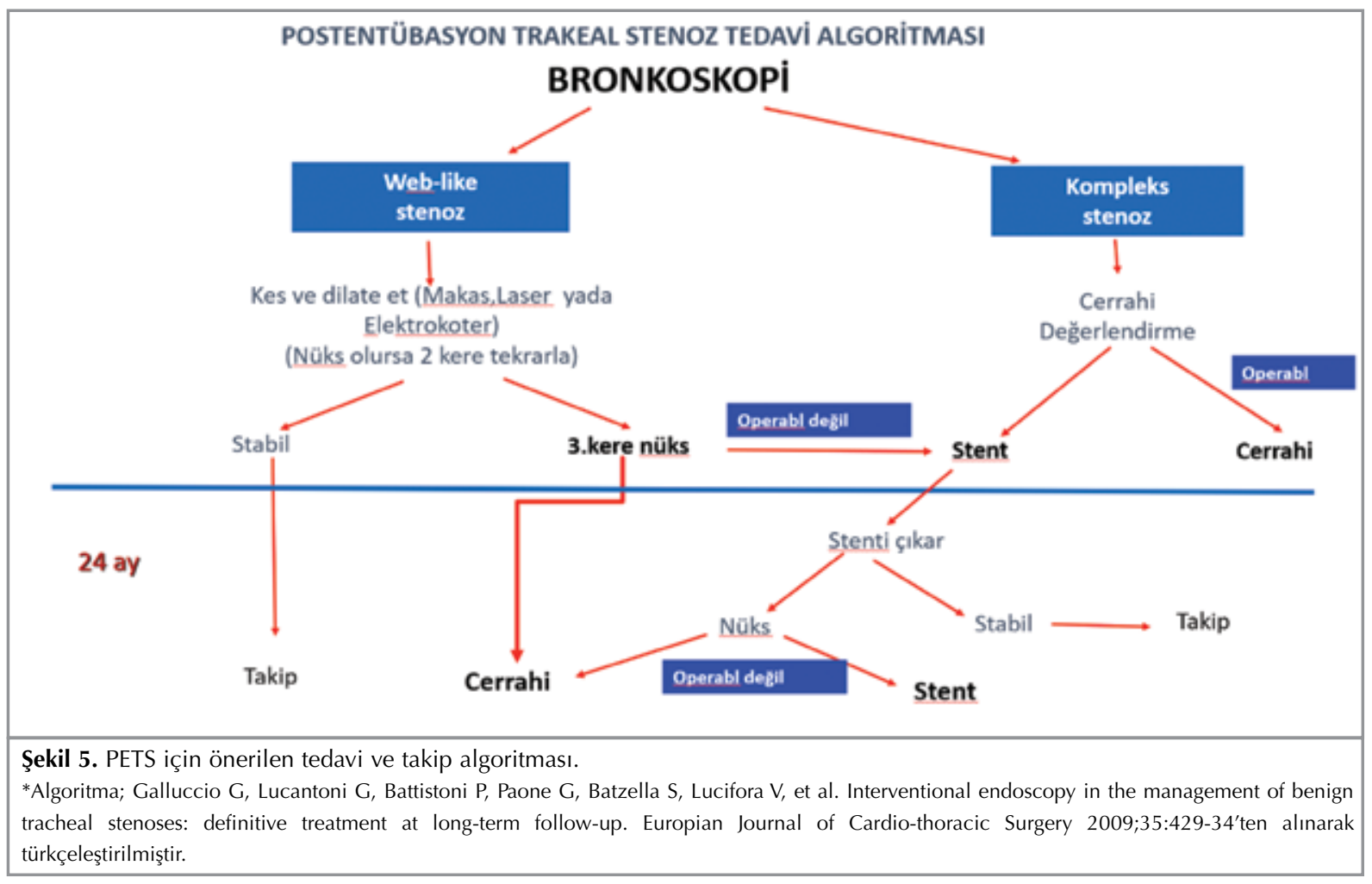

\section{KAYNAKLAR}

1. Lorenz RR. Adult laryngotracheal stenosis: etiology and surgical management. Current Opin Otolaryngol 2003;11:467-72.

2. Stauffer IL, Olson DE, Petty TL. Complications and consequences of endotracheal intubation and tracheotomy: a prospective study of 150 critically ill adult patients. Am J Med 1981;70:65-76.

3. Geffin B, Grillo HC, Cooper JD, Pontoppidan H. Stenosis following tracheostomy for respiratory care. JAMA 1971;216:1984-8

4. Esteller-Moré E, Ibañez J, Matiñó E, Ademà JM, Nolla $M$, Quer IM. Prognostic factors in laryngotracheal injury following intubation and/or tracheotomy in ICU patients. Eur Arch Otorhinolaryngol 2005;262:880-3.

5. Kastanos N, Estopa Miro R, Marin Perez A, Xaubet Mir A, Agusti-Vidal A. Laryngotracheal injury due to endotracheal intubation: incidence, evolution, and predisposing factors. A prospective long-term study. Crit Care Med 1983;11:3627.

6. Herraka L, Ahidb S, Abouqalb R, Lescotc B, Gharbic N. Tracheal stenosis after intubation and/or tracheostomy. Egyptian Journal of Chest Diseases and Tuberculosis 2014;63:233-7.

7. Mathias DB, Wedley JR. The effects of cuffed endotracheal tubes on the tracheal wall. Br J Anaesth 1974;46:849-52.
8. House JC, Noordzij JP, Murgia B, Langmore S. Laryngeal Injury From Prolonged Intubation: a prospective analysis of contributing factors. Laryngoscope 2011;121:596-600.

9. Papla B, Dyduch G, Olechnowicz WFH. Post-intubation tracheal stenosis-morphological-clinical investigations. Pol J Pathol 2003;54:261-6.

10. Ernst A, Silvestri GA, Johnstone D. Interventional pulmonary procedures: guidelines from the american college of chest physicians. Chest 2003;123:1693-717.

11. Grillo HC, Cooper JD, Geffin B, Pontoppidan H. A lowpressure cuff for tracheostomy tubes to minimize tracheal injury. A comparative clinical trial. I Thorac Cardiovasc Surg 1971;62:898-907.

12. De $S$, De S. Post intubation tracheal stenosis. Indian J Crit Care Med 2008;12:194-7.

13. Zias N, Chroneou A, Tabba MK, Gonzales AV, Gray AW, Lamb CR, et al. Post tracheostomy and post intubation tracheal stenosis: report of 31 cases and review of the literatüre. BMC Pulm Med 2008;8:18.

14. Poetker DM, Ettema SL, Blumin JH, Toohill RJ, Merati AL. Association of airway abnormalities and risk factors in 37 subglottic stenosis patients. Curr Opin Oltolaryngol Head Neck Surg 2006;135:434-7.

15. Nicolli EA, Carey RM, Farquhar D, Haft $S$, Alfonso $K P$, Mirza N. Risk factors for adult acquired subglottic stenosis. The Journal of Laryngology\&Otology 2017;131:264-7. 
16. Schweigera C, Manicaa D, Pereirab DRR, Carvalhob PRA, Pivab JP, Kuhla G, et al. Undersedation is a risk factor for the development of subglottic stenosis in intubated children. J Pediatr (Rio J) 2017;93:351-5.

17. Morshed K, Trojanowska A, Szymański M, Trojanowski P, Szymańska A, Smoleń A, et al. Evaluation of tracheal stenosis: comparison between computed tomography virtual tracheobronchoscopy with multiplanar reformatting, flexible tracheofiberoscopy and intra-operative findings. Eur Arch Otorhinolaryngol 2011;268:591-7.

18. Ranu H, Wilde M, Madden B. Pulmonary Function Tests. Ulster Med J 2011;80:84-90.

19. Bacon $L$, Patterson CM, Madden BP. Indications and interventional options for non-resectable tracheal stenosis. J Thorac Dis 2014;6:258-70.

20. Begnaud A, Connett JE, Harwood EM, Jantz MA, Mehta HJ. Measuring central airway obstruction. What Do Bronchoscopists Do? Ann Am Thorac Soc 2015;12:85-90.

21. Ernst $A$, Silvestri $G A$, Johnstone D. Interventional pulmonary procedures: guidelines from the american college of chest physicians. Chest 2003;123:1693-717.

22. Brichet A, Verkindre C, Dupont J, Carlier ML, Darras J, Wurtz A, et al. Multidisciplinary approach to management of postintubation tracheal stenosis. Eur Respir J 1999;13:888-93.

23. Myer CM, O'Connor DM, Cotton RT. Proposed grading system for subglottic stenosis based on endotracheal tube sizes. Ann Otol Rhinol Laryngol 1994;103:319-23.

24. McCaffrey TV. Classification of laryngotracheal stenosis. Laryngoscope 1992;102:1335-40.

25. Grillo HC, Donahue DM. Post intubation tracheal stenosis. Semin Thorac Cardiovasc Surg 1996;8:370-80.

26. Ahn HY, Cho IS, Kim YD, Hoseok I. Surgical outcomes of postintubational posttrachestomy tracheal stenosis: report of 18 cases in single instutition. Ann Thorac Cardiovasc Surg 2015;21:14-7.

27. Foccoli P, Scappaticci E, Rea F, Revello F, Bezzi M, Cavaliere S. Management of post-intubation and/or tracheotomy tracheal stenoses. Monaldi Arch Chest Dis 2011; $75: 182-5$.

28. Rahman NA, Fruchter O, Shitrit D, Fox BD, Kramer MR. Flexible bronchoscopic management of benign tracheal stenosis: long-term follow-up of 115 patients. J Cardiothorac Surg 2010;5:2.

29. Sachdeva A, Pickering EM, Lee HJ. From electrocautery, balloon dilatation, neodymiumdoped:yttrium-aluminumgarnet (Nd:YAG) laser to argon plasma coagulation and cryotherapy. I Thorac Dis 2015;7:363-79.

30. Oh SK, Park KN, Lee SW. Long term results of endoscopic dilatation for tracheal and subglottic stenosis. Clin Exp Otorhinolaryngol 2014;7:324-8.

31. Jung $Y R$, Jeong JT, Lee $M K$, Kim SH, Yong SJ, Lee SJ, et al Recurred post-intubation tracheal stenosis treated with bronchoscopic cryotherapy. Intern Med 2016;55:3331-5.
32. Bhora FY, Ayub A, Forleiter CM, Huang CY, Alshehri $K$, Rehmani S, et al. Treatment of benign tracheal stenosis using endoluminal spray cryotherapy. JAMA Otolaryngol Head Neck Surg 2016;142:1082-7.

33. Jabbardarjani $H$, Kiani A, Sheikhi N. Argon plasma coagulation in treatment of postintubation tracheal stenosis. J Lasers Med Sci 2011;2:49-53.

34. The electrosurgical knife in an optimized intermittent cutting mode for the endoscopic treatment of benign weblike tracheobronchial stenosis. Lutz Freitag and All. Archivos de Bronconeumologia 2012.

35. Gelb AF, Epstein JD. Nd-YAG laser treatment of tracheal stenosis. West J Med 1984;141:472-5.

36. Dutau H, Maldonado F, Laroumagne S, Astoul P. Silicone stents, the rigid bronchoscope, and the standard of care in central airway stenosis. Curr Respir Care Rep 2012;1:4653.

37. Vergnon JM, Costes F, Polio JC. Efficacy and tolerance of a new silicone stent for the treatment of benign tracheal stenosis preliminary results. Chest 2000;118:422-6.

38. Díaz-Jiménez JP, Castro MI, Moya JA. Silicone stents in the management of benign tracheobronchial stenoses tolerance and early results in 63 patients. Chest 1996; 109:626-9.

39. Jose RS, Heinrich DB. Bronchoscopic application of mitomycin-c as adjuvant treatment for benign airway stenosis. Journal of Bronchology\&Interventional Pulmonology 2011;18:53-5.

40. Shadmehr MB, Abbasidezfouli A, Farzanegan R, Pejhan S, Daneshvar A, Sheikhy K, et al. The role of systemic steroids in postintubation tracheal stenosis: a randomized clinical trial. Ann Thorac Surg 2017; 103:246-53.

41. Mehta AC, Lee FY, Cordasco EM, Kirby T, Eliachar I, De Boer G. Concentric tracheal and subglottic stenosis: management using the $\mathrm{Nd}-\mathrm{YAG}$ laser for mucosal sparing followed by gentle dilatation. Chest 1993;104:673-7.

42. Fuller MA, Sigler M, Kambali S, Alalawi R. Successful treatment of post-intubation tracheal stenosis with balloon dilation, argon plasma coagulation, electrocautery and application of mitomycin C. The South West Respiratory and Critical Care Chronicles 2015;3:14-8.

43. Melkane $A E$, Matar NE, Haddad AC, Nassar MN, Almoutran HG, Rohayem Z, et al. Management of postintubation tracheal stenosis: appropriate Indications make outcome differences. Respiration 2010;79:395-401.

44. Galluccio G, Lucantoni G, Battistoni P, Paone G, Batzella $S$, Lucifora $V$, et al. Interventional endoscopy in the management of benign tracheal stenoses: definitive treatment at long-term follow-up. Europian Journal of Cardio-thoracic Surgery 2009;35:429-34. 